\title{
Tratamento lesão tibial D com creme reestruturante
}

\section{Tretament with restructuring cream In Tibial lesion}

\author{
Margrit Gabriela Wilke' • Anderson Luis ${ }^{2}$
}

\section{INTRODUÇÃO}

Estima-se que um entre cada quatro pessoas com diabetes possa desenvolver problemas nos pés ao longo da vida. Segundo a Sociedade Brasileira de Diabetes, a polineuropatia diabética - PND, complicação que atinge $50 \%$ dos pacientes, é a causa mais importante para as úlceras nos pés dos pacientes diabéticos, que precedem $85 \%$ das amputações I,2,3,4. A PND leva a insensibilidade e nos estágios mais avançados, deformidades. A tríade PND + Deformidades + Trauma são fatores determinantes para o chamado "pé diabético", caracterizado por ulceração complicada por infecção e que pode evoluir para amputação, principalmente se há má circulação - a doença arterial obstrutiva crônica (DAOP)3,4,5,6,7,8. Outras condições colocam a pessoa em mais alto risco: doença renal do diabetes (DRD), retinopatia diabética (RD), condição socioeconômica baixa, morar sozinho e inacessibilidade ao sistema de saúde. Segundo o Ministério da Saúde, $70 \%$ das cirurgias para amputação de membros inferiores (pernas, pé, dedos dos pés) no Brasil têm como causa o diabetes mal controlado: são 55 mil amputações anuais4,5,6,7,8.

I. Bacharel em Enfermagem pela Faculdade São Camilo SP; Gestão em Saúde IBMEC São Paulo (2000); MBA em Gestão Financeira nas Organizações de Saúde - PUC SP (2002). Especialização em Enfermagem Dermatológica - Gama Filho;Título Enfermeira Dermatológica pela SOBENFeE (20I3). Profissional com 20 anos de experiência na área da saúde em empresas nacionais e multinacionais, com treinamentos Internacionais pela $\mathrm{KCl}$ - Costa Rica - Health Point- México e Paul Hartmann. Responsável pela estruturação de equipes técnico comercial para lançamento da pressão negativa em território nacional; desenvolvimento de treinamentos teórico-práticos para equipe interna, distribuidores e clientes finais. linkedin.com/in/Gabriela-wilke e-mail: mgabrielawilke@gmail.com

2. Bacharel em Enfermagem pela Faculdade de Enfermagem e Obstetrícia de Fernandópolis-São Paulo;Administração e Gerenciamento nos Serviços de Saúde - CEFOR (1992); Gestão em Administração nos Serviços de Saúde na Rede Municipal e Estadual (SUS) - CEFOR/Santa Casa de Misericórdia de São Paulo (1994); Pesquisador na coordenação de alunos da UNINOVE em moradores de áreas livres (Cracolândia) no tratamento de míase (I996); Especialização em Dermatologia com ênfase em Lesões - UNIFESP (1999); Mestre em Lesões - UNIFESP (2002); Profissional com mais de 30 anos de experiência com lesões;Atual presidente da Comissão de Padronização e Coberturas de Curativos da Secretaria Municipal de Saúde do estado de São Paulo. E-mail:andersonluismartins@hotmail.com 


\section{RELATO DE CASO}

Paciente 78 anos, feminino, afrodescendente, com lesão em Membro Inferior Direito-MID há 10 anos;antecedentes de HAS, Colite, Cardiopatia, DM. Apresenta lesão em região tibial $D$, há 10 anos, com diversos tratamentos realizados, sem o fechamento adequado da lesão. Figura I - Avaliação da lesão em Set/l9. Figura 2 - realizado desbridamento em unidade básica de saúde e início do uso do Creme Reestruturante Hycos. Figura 3 - 30 dias após início do tratamento com Hycos, redução significativa do diâmetro e profundidade da lesão, retração dos bordos. Figura 4 - 56 dias de tratamento, fechamento completo da lesão. Discussão: $O$ tratamento e acompanhamento de pacientes com lesões nos pés diabéticos exige cuidados especializados, adesão do paciente e familiares ao tratamento proposto, sendo um desafio a equipe multidisciplinar. A reparação tecidual e epitelização no paciente idoso com doenças crônicas, levam longo tempo, trazendo impactos psico-sócio econômicos aos pacientes. A escolha do tratamento com creme reestruturante foi baseada na facilidade de uso do produto pelo paciente e familiares, visando a redução das consultas, dos gastos com curativos e produtos, baseada nos princípios ativos naturais de sua fórmula para o desbridamento autolítico, estímulo de angiosenese, manutenção do meio úmido, ação bactericida, ação fungicida e sem contra indicações. Conclusão: $O$ creme reestruturante Hycos, reduziu tempo de tratamento e se mostrou eficaz no estimulo a angiogênese $\mathrm{e}^{9,10}$, com cicatrização completa da lesão em MID dentro de 8 semanas.

Figura I - Avaliação da lesão*

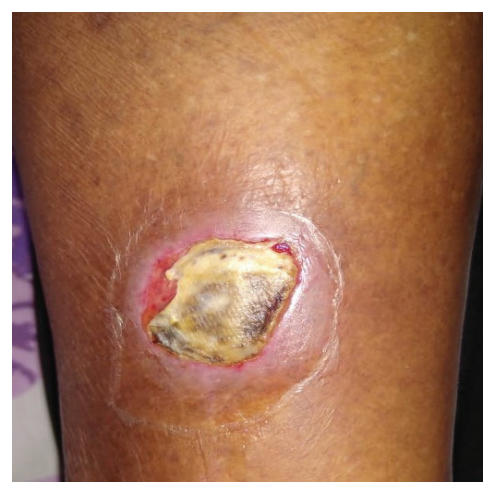

Figura 2 - Desbridamento e início do tratamento*

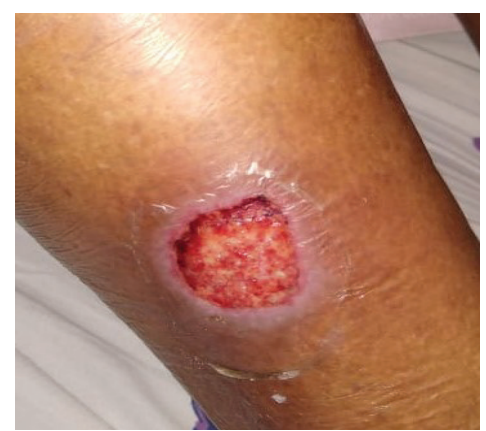

Figura 3 - 03 meses após fechamento da lesão*

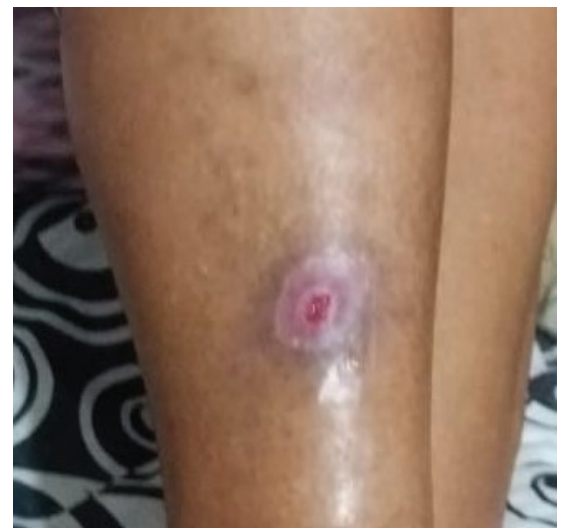

Figura 4- Epitelização total*

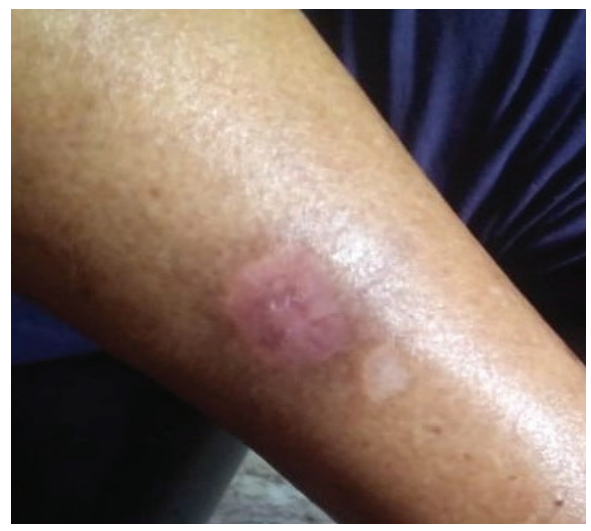

*Fonte: $\mathrm{O}$ autor, 2019. 


\section{REFERÊNCIAS}

I. Sociedade Brasileira de Diabetes. $O$ alto custo do pé diabético no Brasil. Disponível em: https://www.diabetes.org. br/publico/ultimas/ /609-o-alto-custo-do-pe-diabetico-no -brasil.Acesso em: 12 mar. 2020.

2. Sociedade Brasileira de Diabetes. Posicionamento Oficial SBD n. 01/2019: Conduta Terapêutica No Diabetes Tipo 2: Algoritmo SBD 2019. São Paulo: SBD; 2019. Disponível em: https://www.diabetes.org.br/publico/images/pdf/sbd_ dm2_2019_2.pdf.Acesso em: 12 out. 2019.

3. Brasil. Ministério da Saúde. Secretaria de Atenção à Saúde. Departamento de Atenção básica. Manual do pé diabético: estratégias para o cuidado da pessoa com doença crônica. Brasília: Ministério da Saúde; 2016.

4. São Paulo. Secretaria Municipal de Saúde. Programa de prevenção e tratamento de úlceras crônicas e do pé diabético. Protocolo de prevenção e tratamento de úlceras crônicas e do pé diabético. São Paulo; 2009.

5. Maia TF et al. $O$ pé diabético de clientes e seu autocuidado. Esc.Anna Nery R Enferm. 2005 Abr 9(I):95-102.

6. Grossi SAA. Prevenção de úlceras nos membros inferiores em pacientes com diabetes mellitus. Rev. Ese. Enf. USP. 1998 Dez 3(4):377-385.

7. Sociedade Brasileira de Diabetes. Diagnóstico precoce do Pé Diabético. In: Sociedade Brasileira de Diabetes. Tratamento e acompanhamento do diabetes mellitus: diretrizes da Sociedade Brasileira de Diabetes. SBD; 2007. p. II7-II9. Disponível em: http://www.cff.org.br/userfiles/file/noticias/Diretrizes_SBD_2007\%5BI\%5D.pdf. Acesso em: 12 fev. 2020.

8. International Working Group on the Diabetic Foot. Diretivas práticas sobre o tratamento e prevenção do pé diabético: Com base no Consenso Internacional sobre o pé diabético. IWGDF; $201 \mathrm{I}$.

9. Grupo De Trabalho Internacional Sobre Pé Diabético. Consenso Internacional sobre pé diabético. Brasília, DF: Secretaria de Estado da Saúde do Distrito Federal; 200I. 100 p.

10. HESS CT. Tratamento de feridas e úlceras. 4. ed. Rio de Janeiro: Reichemann \& Affonso Editores; 2002.

Recebido: 2020-02-04

Aceito: 2020-03-10 